\title{
A cross-sectional pilot study to investigate diabetic knowledge and pharmaceutical care practice among registered and unregistered pharmacists in Iraq
}

\author{
Shaymaa Abdalwahed Abdulameer* \\ Faculty of Pharmacy, Al-Rafidain University College, Baghdad, Iraq.
}

\section{ARTICLE INFO \\ Received on: 09/07/2018 \\ Accepted on: 23/09/2018 \\ Available online: $31 / 10 / 2018$}

\section{Key words:}

Diabetes, Knowledge,

Pharmaceutical care,

Pharmacists, Practice.

\begin{abstract}
Pharmacists have crucial roles beyond dispensing medications. Hence, the present study aimed to assess the knowledge and pharmaceutical care practice towards diabetes mellitus (DM) among unregistered and registered community pharmacists in Iraq. An observational cross-sectional pilot study with a random cluster sampling method was carried out among registered and unregistered pharmacists in Baghdad. The study included three sections: the background and demographic information, diabetes knowledge test (DKT), and pharmaceutical care practice questionnaire. The mean total DKT, knowledge of general diabetes, and insulin use test subscales scores were $13.45 \pm 3.36,8.39 \pm 2.22$, and $5.06 \pm 1.77$, respectively, which revealed an inadequate knowledge. There were significant differences in the total DKT score with the university type and educational levels. Moreover, the diabetic care practice of the registered pharmacists were moderate $(16.92 \pm 4.28)$ and only $30.60 \%$ had positive practice. The highest and the lowest positive practice frequencies were found in blood glucose monitoring care (38.20\%) and co-morbid DM disease management $(21.20 \%)$, respectively. Furthermore, there were positive correlations between the total DKT and its subscales scores with the total diabetic care practice score. The results revealed that professional knowledge and practice toward DM among the sample population were inadequate. Hence, pharmaceutical care practices are a major concern in Iraq.
\end{abstract}

\section{INTRODUCTION}

In primary and secondary healthcare sectors, diabetes mellitus (DM) is the most significant healthcare problem due to its microvascular and macrovascular complications (American Diabetes Association, 2014). Moreover, the prevalence of DM in 2014 was 387 million people worldwide and it is expected to increase to 592 million in 2035 (Guariguata et al., 2014). Now a day, pharmacists are involved in new roles due to the evolution of pharmaceutical care to improve patients' use of medications and quality of life (Hermansen-Kobulnicky and Worley, 2008). However, the previous report showed limited evidence of the effectiveness of community pharmacy-based diabetes care intervention. This is almost due to

"Corresponding Author

Shaymaa Abdalwahed Abdulameer, Faculty of Pharmacy, Al-Rafidain University College, E-mail: Abdulameerxbm2004@yahoo.com healthcare services for diabetic patients are provided in the primary care setting, even though, community pharmacy-based services could improve diabetic care (Blenkinsopp and Hassey, 2005).

Pharmacists have a crucial role beyond dispensing medication as they have to be well trained to provide pharmaceutical care services (Smith, 2009; Karter et al., 2015). With these services, medications adherence and medications literacy will be enhanced, as well as, medication errors will be reduced (Brennan et al., 2012; Kraemer et al., 2012; Wertz et al., 2012; Shareef, 2018). As a result, diabetic patients will have a good control and better health outcome for their condition with a lower overall healthcare expenditure (Perez et al., 2009; Touchette et al., 2014). Many factors affect pharmacists overall healthcare services that provided such as culture obstacles, pharmacist training, and collaboration with the other healthcare providers. Therefore, healthcare services and activity will vary from pharmacy to pharmacy and even from pharmacist to pharmacist in the same pharmacy (Shatnawi and Latif, 2016). 
In Iraq, there was no exact figure of diabetes prevalence from government authority. But a recent report from the International Diabetes Federation (IDF) in 2015 showed that 1.2 million cases of diabetes among adults in Iraq (International Diabetes Federation, 2017). A recent community-based study in Basrah (a southern city in Iraq) showed that the prevalence of DM in this area for diagnosed and undiagnosed diabetic patient was 19.7\% (Mansour et al., 2014). Therefore, diabetes disease is an increasing problem and underestimated in Iraq and needs an urgent health policy to overcome this problem. Therefore, the knowledge and practice of the community pharmacists must be evaluated before any implementation of any educational program either for diabetic patients and/or for the general population. Hence, the aims of this pilot study were to assess the diabetes knowledge and pharmaceutical care practice among registered and unregistered pharmacists in Baghdad, Iraq.

\section{MATERIALS AND METHODS}

\section{Study design and participants}

An observational, cross-sectional pilot study was carried from November 2016 to April 2017 in Baghdad capital, Iraq. Random cluster sampling method was used to select three areas from two large distract zone named Al-Kharkh (west of the Tigris: four distract zone) and Al-Rusafa (east of the Tigris: six distract zones). Inclusion criteria were pharmacists must be a member in Syndicate of Iraqi Pharmacists (SIP) and only one pharmacist from each pharmacy was involved in the study. All retail pharmacies from these areas were visited by the researcher. Pharmacists declining participation at this initial contact were excluded from the study.

Moreover, unregistered pharmacists (pharmacists freshly graduated from the college of pharmacy and not members in SIP) were invited to participate during the registration meeting governed by SIP. Before participation in this study, all participants were provided with a written informed consent. The study protocol and ethical approval were approved by the Scientific Committee of Al-Rafidain University College in Baghdad, Iraq.

Sample size was calculated according to the Cochran formula (Cochran, 1977). Two recent reports in Arabic regions showed that the proportions of the pharmacists who had an incorrect response regarding diabetes knowledge were $30.40 \%$ and 25\% (Bisheya et al., 2011; El Hajj et al., 2017). By applying the two values in the Cochran formula, the results revealed a sample size of 325 and 288, respectively. Therefore, the sample of the larger figure was chosen for this study.

\section{Instruments}

Face-to-face interviews included the collection of three sections: the background and demographic information, diabetes knowledge test (DKT), and pharmaceutical care practice questionnaires. All tools were administered in the English language. The DKT is 23 multiple-choice items to assess the general knowledge of diabetes with two subscales: knowledge of general diabetes test subscale (1-14) and knowledge of insulin use test subscale (15-23). The DKT was obtained from the Michigan Diabetes Research Training Center [a project supported by the
National Institute of Diabetes and Digestive and Kidney Diseases, Grant Number P30DK092926]. In addition, the pharmaceutical care practice questionnaire was modified from previous reports to measure the registered community pharmacists pharmaceutical care practice (Simpson et al., 2009; Abdulameer, 2018). It is a 4-Likert type scale (Never, score 1; Always, score 4 with a total score range from 6 to 24). Practice was classified in to two categories: positive practice and negative practice according to the previous report (Shrestha et al., 2015).

\section{Statistical analysis}

Three levels of pharmacists' knowledge were generated (low, medium, and high) according to the previous report (Shrestha et al., 2015). Furthermore, to assess the pharmacists' distribution regarding their diabetes knowledge and practice, mean deviations were calculated and a plot between the two variables was constructed. This result in four quadrants namely: first quadrant (good knowledge and positive practice), second quadrant (good knowledge and negative practice), third quadrant (low knowledge and positive practice), and the fourth quadrant (low knowledge and negative practice). The significance level was set at a $p$ value $<0.05$ using Predictive Analytics Software version 19.0. The chisquare $\left(\chi^{2}\right)$, Mann-Whitney $U$ and Kruskal-Wallis tests were used to evaluate the association and differences. Spearman correlation was used to measure the correlation between continuous variables when appropriate.

\section{RESULTS}

\section{Response rate and demographic}

Out of 300 community pharmacies reached, only 170 registered pharmacists agree to participate with a response rate equal to $56.60 \%$. For unregistered pharmacists, 170 participants were randomly selected out of 350 . This number was chosen for statistical reasons to compare them with the registered pharmacists. Therefore, the total sample size was 340. The collected demographic characteristics of the study respondents are presented in Table 1.

For registered pharmacists, the mean age was 31.62 \pm 8.66 . The average diabetic patient's number seen weekly and pharmacists working experiences were $15.86 \pm 14.41$ years and 7.61 \pm 7.59 years, respectively. More than half of the respondents were male $(52.40 \%)$ and work at both government and private sectors $(54.10 \%)$. More than three-quarter of the registered pharmacists were graduated from government universities $(81.20 \%)$ with a bachelor degree $(89.40 \%)$ and working at urban areas $(82.40 \%)$. The most common source of information that the pharmacists obtained about diabetes was by the undergraduate study $(57.10 \%)$ followed by the postgraduate study $(15.30 \%)$. The most common answer regarding who educate the patient about the disease was "either the doctor or the pharmacist (54.10\%)." The most primary obstacle in diabetic care services was the lack of training $(54.10 \%)$.

For the unregistered pharmacists, the mean age was $24.75 \pm 2.55$. More than half of them were female $(64.70 \%)$, graduated from private university $(68.20 \%)$ with bachelor studies $(100 \%)$. The most common source of information that the pharmacists obtained about DM was from the undergraduate study (72.40\%) followed by reading articles or specialized books $(20.60 \%)$. The most common 
Table 1. The demographic characteristics of the pharmacists.

\begin{tabular}{|c|c|c|c|}
\hline Characteristics & $\begin{array}{l}\text { Registered pharmacists } \\
\qquad(N=170)\end{array}$ & $\begin{array}{l}\text { Unregistered pharmacists } \\
\qquad(N=170)\end{array}$ & $\begin{array}{l}\text { Total DKT score } \\
\qquad(N=340)\end{array}$ \\
\hline Age (year) & $31.62 \pm 8.66$ & $24.75 \pm 2.55$ & $13.45 \pm 3.36$ \\
\hline Average number diabetic patient/week & $15.86 \pm 14.41$ & ---- & ----- \\
\hline Working experience (Year) & $7.61 \pm 7.59$ & ---- & ---- \\
\hline \multicolumn{4}{|l|}{ Gender } \\
\hline Male & $52.40 \%$ & $35.30 \%$ & $13.05 \pm 3.54$ \\
\hline Female & $47.60 \%$ & $64.70 \%$ & $13.77 \pm 3.19$ \\
\hline \multicolumn{4}{|l|}{ University type $\mathrm{a}^{\mathrm{a}}$} \\
\hline Government & $81.20 \%$ & $31.80 \%$ & $13.88 \pm 3.25$ \\
\hline Private & $18.80 \%$ & $68.20 \%$ & $12.90 \pm 3.43$ \\
\hline \multicolumn{4}{|l|}{ Educational level $\mathrm{l}^{\mathrm{b}}$} \\
\hline Bachelor degree & $89.40 \%$ & $100 \%$ & $13.36 \pm 3.34$ \\
\hline Diploma & $8.80 \%$ & $0.0 \%$ & $14.80 \pm 3.41$ \\
\hline Master & $1.80 \%$ & $0.0 \%$ & $17.00 \pm 2.65$ \\
\hline \multicolumn{4}{|l|}{ Employment status } \\
\hline Private & $24.70 \%$ & ---- & $14.29 \pm 2.81$ \\
\hline Government & $21.20 \%$ & ---- & $14.44 \pm 3.15$ \\
\hline Both & $54.10 \%$ & ---- & $15.02 \pm 2.95$ \\
\hline \multicolumn{4}{|l|}{ Pharmacy or hospital located area } \\
\hline Rural & $17.60 \%$ & ---- & $14.27 \pm 2.72$ \\
\hline Urban & $82.40 \%$ & $-\cdots--$ & $14.81 \pm 3.01$ \\
\hline \multicolumn{4}{|l|}{ Information obtained about diabetes ${ }^{a}$} \\
\hline Undergraduate study & $57.10 \%$ & $72.40 \%$ & $13.65 \pm 3.31$ \\
\hline Postgraduate study & $15.30 \%$ & $0.0 \%$ & $12.80 \pm 3.76$ \\
\hline Attending meeting and workshop & $7.60 \%$ & $7.10 \%$ & $11.58 \pm 2.94$ \\
\hline Reading article or book specialized & $10.60 \%$ & $20.60 \%$ & $14.39 \pm 2.73$ \\
\hline Continuing education course & $9.40 \%$ & $0.0 \%$ & $15.00 \pm 2.85$ \\
\hline \multicolumn{4}{|l|}{ Who train the patient about diabetic care ${ }^{b}$} \\
\hline Pharmacist & $11.80 \%$ & $22.40 \%$ & $12.19 \pm 3.29$ \\
\hline Doctor & $18.20 \%$ & $17.10 \%$ & $13.82 \pm 3.43$ \\
\hline Nurse & $5.90 \%$ & $2.40 \%$ & $11.93 \pm 3.58$ \\
\hline $\begin{array}{l}\text { Collaboration between the doctor and } \\
\text { the pharmacist }\end{array}$ & $54.10 \%$ & $50.60 \%$ & $13.78 \pm 3.29$ \\
\hline $\begin{array}{l}\text { Collaboration between the doctor and } \\
\text { the nurse }\end{array}$ & $7.60 \%$ & $7.60 \%$ & $13.85 \pm 3.21$ \\
\hline $\begin{array}{l}\text { Collaboration between the pharmacist } \\
\text { and the nurse }\end{array}$ & $2.40 \%$ & $0.0 \%$ & $14.50 \pm 2.65$ \\
\hline \multicolumn{4}{|l|}{ Primary obstacle in diabetic care services } \\
\hline Time constraints & $34.70 \%$ & $-\cdots--$ & $14.51 \pm 2.83$ \\
\hline Lack of training & $54.10 \%$ & $-\cdots--$ & $14.85 \pm 3.18$ \\
\hline Lack of reimbursement & $11.20 \%$ & ---- & $14.74 \pm 2.31$ \\
\hline
\end{tabular}

Significant difference between groups, ${ }^{a} p<0.01$; ${ }^{b} p<0.05$.

answer regarding who educate the patient about the disease was "either the doctor or pharmacist (50.60\%)."

\section{Diabetic knowledge}

For 340 respondents, the total DKT score, knowledge of general diabetes test subscale, and knowledge of insulin use test subscale scores were $13.45 \pm 3.36,8.39 \pm 2.22$, and $5.06 \pm$ 1.77 , respectively, which revealed poor knowledge regarding diabetes disease for all pharmacists. For registered community pharmacists, the total DKT score, knowledge of general diabetes test subscale, and knowledge of insulin use test subscale scores were $14.72 \pm 2.96,8.85 \pm 2.13$, and $5.87 \pm 1.47$, respectively. While for unregistered pharmacists, the total DKT score, the two subscales scores were $12.19 \pm 3.26,7.94 \pm 2.23$, and $4.25 \pm 1.66$, respectively. Only $16.50 \%$ of the study population was found to have high DKT scores, while $35.30 \%$ were found to have low scores, as shown in Table 2.

The results showed that registered community pharmacists had higher diabetic knowledge in all subscales than unregistered pharmacists $(p<0.01)$. There were significant 
Table 2. Distribution of the three diabetic knowledge levels $(N=340)$.

\begin{tabular}{lccc}
\hline Variable & Mean \pm standard deviation & Frequency & Percent \\
\hline DKT level & $13.45 \pm 3.36$ & ---- & ---- \\
Low knowledge scores $(<12)$ & $9.92 \pm 2.26$ & 120 & 35.30 \\
Medium knowledge scores $(13-16)$ & $14.38 \pm 1.05$ & 164 & 48.20 \\
High knowledge scores $(>17)$ & $18.29 \pm 1.35$ & 56 & 16.50 \\
\hline
\end{tabular}

Table 3. Correct answer percentages of DKT and its two subscales.

\begin{tabular}{|c|c|c|c|c|c|c|c|c|c|}
\hline \multirow[b]{2}{*}{ Characteristics } & \multicolumn{3}{|c|}{ DKT total score* } & \multicolumn{3}{|c|}{ Knowledge of general diabetes test subscale* } & \multicolumn{3}{|c|}{ Knowledge of Insulin use test subscale* } \\
\hline & $\begin{array}{c}\text { Total sample } \\
(N=\mathbf{3 4 0})\end{array}$ & $\begin{array}{c}\text { Registered } \\
\text { pharmacists } \\
(N=170)\end{array}$ & $\begin{array}{c}\text { Unregistered } \\
\text { pharmacists } \\
\qquad(N=170)\end{array}$ & $\begin{array}{l}\text { Total sample } \\
(N=\mathbf{3 4 0})\end{array}$ & $\begin{array}{c}\text { Registered } \\
\text { pharmacists } \\
(N=170)\end{array}$ & $\begin{array}{c}\text { Unregistered } \\
\text { pharmacists } \\
(N=170)\end{array}$ & $\begin{array}{c}\text { Total sample } \\
(N=340)\end{array}$ & $\begin{array}{c}\text { Registered } \\
\text { pharmacists } \\
(N=170)\end{array}$ & $\begin{array}{c}\text { Unregistered } \\
\text { pharmacists } \\
(N=170)\end{array}$ \\
\hline Mean \pm SD & $13.45 \pm 3.36$ & $14.72 \pm 2.96$ & $12.19 \pm 3.27$ & $8.39 \pm 2.22$ & $8.85 \pm 2.13$ & $7.94 \pm 2.23$ & $5.06 \pm 1.77$ & $5.87 \pm 1.47$ & $4.25 \pm 1.66$ \\
\hline Potential range & $0-23$ & $0-23$ & $0-23$ & $0-14$ & $0-14$ & $0-14$ & $0-9$ & $0-9$ & $0-9$ \\
\hline Correct \% & $58.48 \%$ & $64 \%$ & $53 \%$ & $59.93 \%$ & $63.21 \%$ & $56.71 \%$ & $56.22 \%$ & $65.22 \%$ & $47.22 \%$ \\
\hline
\end{tabular}

*Significant difference between groups $(p<0.01)$.

differences in the total DKT score with the university type and educational level ( $p<0.01$ and $p<0.05$, respectively). The results showed that pharmacists graduated from government universities and master degree holders had higher DKT scores. In addition, there was a significant difference in the total DKT score with the source of information obtained about the diabetic disease $(p<0.01)$.

The DKT score of the pharmacists who had continuous educational courses was significantly higher than pharmacists attending meeting and workshop. The results showed that the pharmacists who believe that the collaboration between the doctor and the pharmacist regarding patient education had higher total DKT score than others $(p<0.05)$. Moreover, there was a significant correlation between the total DKT score and age $(r=0.27, p<0.01)$. Finally, the results showed insignificant differences between DKT score with gender, employment status, pharmacy or hospital located area, and the primary obstacle in diabetic care services $(p>0.05)$.

\section{Frequency of correct responses to diabetic knowledge test}

Table 3 shows the distribution of the correct answers percentage of knowledge among the study respondents. Overall, the mean percentage of the correct answers of the DKT for the total sample, registered, and unregistered pharmacists were $58.48 \%$, $64 \%$, and $53 \%$, respectively. Only one pharmacist answered all the knowledge test questions correctly and got a score of 23, while no pharmacists answered all the questions incorrectly and got a score of 0 . The percentage of the correct answers for each question in the DKT was calculated (Table 4).

Out of 23 questions, only seven questions were answered incorrectly by more than $50 \%$ of registered community pharmacists. These questions are related to the food highest in fat (Question 3), free food (Question 4), effect of unsweetened fruit juice (Question 7), treatment of low blood glucose (Question 8), recognition of signs of diabetic ketoacidosis (DKA) (Question 15), insulin use (Question 17), and hypoglycemia treatment among insulin user (Question 19). Unexpectedly, 11 questions were answered incorrectly by more than $50 \%$ of unregistered pharmacists (Questions 3, 4, 5, 7, 8, $10,15,17,18,19$, and 23) as shown in Table 4.

\section{Diabetic care practice among registered pharmacists}

The diabetic care practice score of the registered community pharmacists was $16.92 \pm 4.28$ and only $30.60 \%$ had positive pharmaceutical care practice. The highest and the lowest positive practice frequencies were found in blood glucose monitoring care (38.20\%) and co-morbid DM disease management (21.20\%), respectively. Regarding negative practice, counseling about co-morbid DM disease management was never practiced by $19.40 \%$ of the respondents.

In addition, $25.90 \%$ of the respondents were rarely practicing sick day DM care. Moreover, counseling about healthy living choices regarding DM was often practiced by $39.40 \%$ of the respondents (Table 5). According to the mean deviation calculation, the first quadrant showed that only $41.17 \%$ of the respondents had good knowledge as well as positive practice regarding DM. Additionally, 15.29\% of the respondents (fourth quadrant) showed low knowledge and negative practice. All quadrants results are represented in Figure 1.

\section{Correlation measurements}

There were positive correlations between the total diabetic care practice score with the total DKT, knowledge of general diabetes test subscale, and knowledge of insulin use test subscale scores $(r=0.22, p<0.01),(r=0.17, p<0.05)$ and $(r=0.21, p<0.01)$, respectively. Moreover, there were positive correlations between pharmacotherapy care practice with the total DKT score $(r=0.33, p<0.01)$ and knowledge of general diabetes test subscale score $(r=0.17, p<0.05)$. In addition, there were positive correlations between knowledge of insulin use test subscale score with hypoglycemia care practice $(r=0.16, p<0.05)$, pharmacotherapy care practice $(r=0.37, p$ $<0.01)$, and co-morbid diabetes disease care practice $(r=0.29$, $p<0.01)$.

\section{DISCUSSION}

Patient education besides treatment must be considered for any disease management which is a crucial role for the pharmacists (Borges et al., 2011). The response rate is considered 
Table 4. The answers' frequencies of the DKT.

\begin{tabular}{|c|c|c|c|}
\hline $\mathbf{S} / \mathbf{N}$ & Questions & $\begin{array}{l}\text { Registered pharmacists (\%) } \\
\qquad(N=170)\end{array}$ & $\begin{array}{l}\text { Unregistered pharmacists (\%) } \\
(N=170)\end{array}$ \\
\hline \multirow[t]{5}{*}{1.} & The diabetes diet is & & \\
\hline & A. The way most people eat. & 8.20 & 10.60 \\
\hline & B. A healthy diet for most people. & 67.10 & 63.50 \\
\hline & C. Too high in carbohydrate for most people. & 13.50 & 14.10 \\
\hline & D. Too high in protein for most people. & 11.20 & 11.80 \\
\hline \multirow[t]{5}{*}{2.} & Which of the following is highest in carbohydrate? & & \\
\hline & A. Baked chicken. & 4.10 & 4.10 \\
\hline & B. Swiss cheese. & 4.70 & 6.50 \\
\hline & C. Baked potato. & 77.10 & 74.70 \\
\hline & D. Peanut butter. & 14.10 & 14.70 \\
\hline \multirow[t]{5}{*}{3.} & Which of the following is highest in fat? & & \\
\hline & A. Low fat (2\%) milk. & 31.80 & 43.50 \\
\hline & B. Orange juice. & 2.40 & 1.80 \\
\hline & C. Corn. & 60.60 & 47.10 \\
\hline & D. Honey. & 5.30 & 7.60 \\
\hline \multirow[t]{5}{*}{4.} & Which of the following is a "free food"? & & \\
\hline & A. Any unsweetened food. & 11.80 & 10 \\
\hline & B. Any food that has "fat free" on the label. & 18.20 & 10 \\
\hline & C. Any food that has "sugar free" on the label. & 40 & 36.50 \\
\hline & D. Any food that has less than 20 calories per serving. & 30 & 43.50 \\
\hline \multirow[t]{5}{*}{5.} & A1C is a measure of your average blood glucose level for the past: & & \\
\hline & A. day. & 4.10 & 11.20 \\
\hline & B. week. & 3.50 & 14.10 \\
\hline & C. 6-12 weeks. & 62.90 & 44.10 \\
\hline & D. 6 months. & 29.40 & 30.60 \\
\hline \multirow[t]{4}{*}{6.} & Which is the best method for home glucose testing? & & \\
\hline & A. Urine testing. & 1.20 & 4.70 \\
\hline & B. Blood testing. & 85.90 & 74.70 \\
\hline & C. Both are equally good. & 12.90 & 20.60 \\
\hline \multirow[t]{4}{*}{7.} & What effect does unsweetened fruit juice have on blood glucose? & & \\
\hline & A. Lowers it. & 11.80 & 21.80 \\
\hline & B. Raises it. & 30.60 & 25.30 \\
\hline & C. Has no effect. & 57.60 & 52.90 \\
\hline \multirow[t]{5}{*}{8.} & Which should not be used to treat low blood glucose? & & \\
\hline & A. 3 hard candies. & 24.10 & 39.40 \\
\hline & B. $1 / 2$ cup orange juice. & 11.20 & 13.50 \\
\hline & C. 1 cup diet soft drink. & 41.20 & 22.90 \\
\hline & D. 1 cup skim milk. & 23.50 & 24.10 \\
\hline \multirow[t]{4}{*}{9.} & $\begin{array}{l}\text { For a person in good control, what effect does exercise have on } \\
\text { blood glucose? }\end{array}$ & & \\
\hline & A. Lowers it. & 68.80 & 75.90 \\
\hline & B. Raises it. & 14.10 & 11.80 \\
\hline & C. Has no effect. & 17.10 & 12.40 \\
\hline \multirow[t]{4}{*}{10.} & What effect will an infection most likely have on blood glucose? & & \\
\hline & A. Raises it. & 62.90 & 44.70 \\
\hline & B. Lowers it. & 4.70 & 15.90 \\
\hline & C. Has no effect. & 32.40 & 39.40 \\
\hline \multirow[t]{2}{*}{11.} & The best way to take care of your feet is to: & & \\
\hline & A. look at and wash them each day. & 64.10 & 51.20 \\
\hline
\end{tabular}




\begin{tabular}{llcc}
\hline S/N & Questions & $\begin{array}{c}\text { Registered pharmacists }(\%) \\
(\boldsymbol{N}=\mathbf{1 7 0})\end{array}$ & $\begin{array}{c}\text { Unregistered pharmacists }(\mathbf{\%}) \\
(\boldsymbol{N}=\mathbf{1 7 0})\end{array}$ \\
\hline B. Massages them with alcohol each day. & 10 & 14.70 \\
C. Soak them for 1 hour each day. & 5.30 & 12.90 \\
D. Buy shoes a size larger than usual. & 20.60 & 21.20
\end{tabular}

12. Eating foods lower in fat decreases your risk for:

$\begin{array}{lcr}\text { A. nerve disease. } & 7.10 & 8.20 \\ \text { B. kidney disease. } & 5.30 & 17.10 \\ \text { C. } \text { heart disease. } & \mathbf{8 0} & \mathbf{6 5 . 3 0} \\ \text { D. eye disease. } & 7.60 & 9.40\end{array}$

13. Numbness and tingling may be symptoms of:

A. kidney disease.

B. nerve disease.

C. eye disease.

D. liver disease.

14. Which of the following is usually not associated with diabetes:
A. vision problems.
B. kidney problems.
C. nerve problems.

15. Signs of ketoacidosis (DKA) include:
A. shakiness
B. sweating.
D. low blood glucose.

16. If you are sick with the flu, you should:
A. Take less insulin.
B. Drink fewer liquids.

C. Eat more proteins.

\section{Test blood glucose more often.}

62.90

17. If you have taken rapid-acting insulin, you are most likely to have a low blood glucose reaction in:

\section{A. Less than 2 hours.}

B. $3-5$ hours

C. 6-12 hours.

D. More than 13 hours.

18. You realize just before lunch that you forgot to take your insulin at breakfast. What should you do now?

A. Skip lunch to lower your blood glucose.

B. Take the insulin that you usually take at breakfast.

C. Take twice as much insulin as you usually take at breakfast.

D. Check your blood glucose level to decide how much insulin to take.

19. If you are beginning to have a low blood glucose reaction, you should:

\begin{tabular}{ll}
20.60 & 14.10 \\
13.50 & 28.20 \\
34.70 & $\mathbf{2 7 . 1 0}$ \\
31.20 & 30.60 \\
& \\
$\mathbf{9 4 . 7 0}$ & $\mathbf{7 2 . 4 0}$ \\
3.50 & 7.10 \\
0.60 & 11.20 \\
\hline
\end{tabular}

34.70

41.20

15.90

8.20

48.80

B. lie down and rest.

7.10

\section{C. drink some juice.}

D. take rapid-acting insulin.

20. A low blood glucose reaction may be caused by:

A. too much insulin.

7.10

C. too much food. 


\begin{tabular}{|c|c|c|c|}
\hline $\mathrm{S} / \mathrm{N}$ & Questions & $\begin{array}{l}\text { Registered pharmacists (\%) } \\
\qquad(N=170)\end{array}$ & $\begin{array}{l}\text { Unregistered pharmacists }(\%) \\
\qquad(N=170)\end{array}$ \\
\hline & D. too little exercise. & 1.20 & 9.40 \\
\hline \multirow[t]{4}{*}{21.} & $\begin{array}{l}\text { If you take your morning insulin but skip breakfast, your blood glucose } \\
\text { level will usually: }\end{array}$ & & \\
\hline & A. increase. & 12.90 & 14.10 \\
\hline & B. decrease. & 81.20 & 63.50 \\
\hline & C. remain the same. & 5.90 & 22.40 \\
\hline \multirow[t]{5}{*}{22.} & High blood glucose may be caused by: & & \\
\hline & A. not enough insulin. & 86.50 & 57.60 \\
\hline & B. skipping meals. & 4.70 & 11.20 \\
\hline & C. delaying your snack. & 1.80 & 10 \\
\hline & D. skipping your exercise. & 7.10 & 21.20 \\
\hline \multirow[t]{5}{*}{23.} & A low blood glucose reaction may be caused by: & & \\
\hline & A. heavy exercise. & 41.20 & 26.50 \\
\hline & B. infection. & 27.10 & 28.80 \\
\hline & C. overeating. & 19.40 & 24.70 \\
\hline & D. not taking your insulin. & 12.40 & 20 \\
\hline
\end{tabular}

Correct answer appears in bold and Italic font.

Table 5. Diabetic care practice for registered community pharmacists in Iraq $(N=170)$.

\begin{tabular}{|c|c|c|c|c|c|}
\hline $\begin{array}{c}\text { Diabetic care } \\
\text { practice }\end{array}$ & & Never $(\%)$ & Rarely (\%) & Often $(\%)$ & Always (\%) \\
\hline 1. & Do you evaluate blood glucose monitoring? & 9.40 & 18.20 & 34.10 & 38.20 \\
\hline 2. & Do you assess hypoglycemia Management? & 10 & 22.4 & 31.2 & 36.5 \\
\hline 3. & Do you assess sick day management? & 14.10 & 25.90 & 34.10 & 25.90 \\
\hline 4. & Do you assess pharmacotherapy? & 18.20 & 22.90 & 32.90 & 25.90 \\
\hline 5. & Do you assess comorbid disease management? & 19.40 & 23.50 & 35.90 & 21.20 \\
\hline 6. & Do you assess healthy living choices? & 9.40 & 16.50 & 39.40 & 34.70 \\
\hline
\end{tabular}

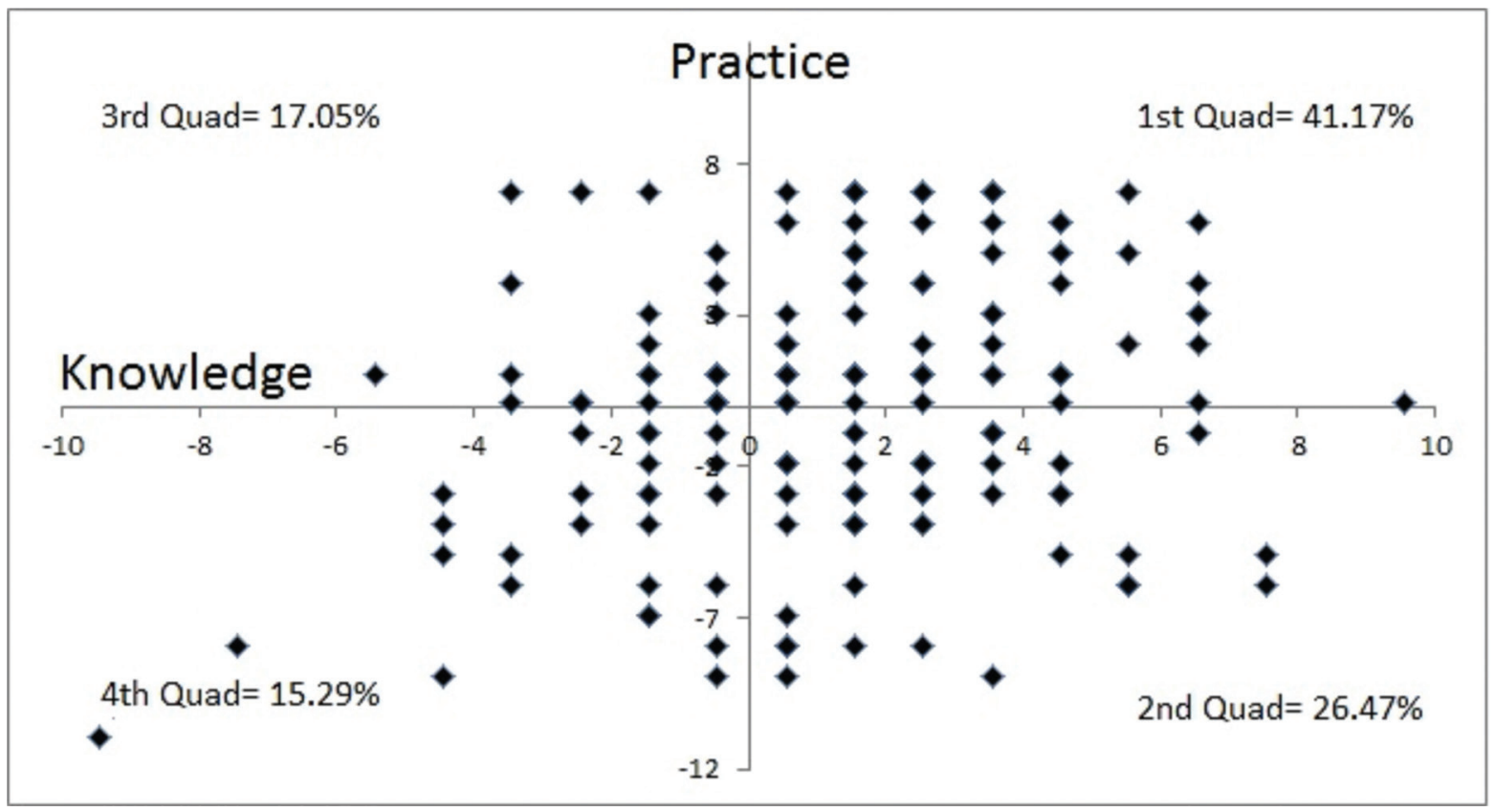

Figure 1. Knowledge and practice distribution among registered community pharmacists $(N=170)$. [Quad: quadrant; first quadrant (good knowledge and positive practice); second quadrant (good knowledge and negative practice); third quadrant (low knowledge and positive practice); fourth quadrant (low knowledge and negative practice)]. 
low but it was higher than other Arabic study (El Hajj et al., 2017). The reasons behind this low figure were lack of time and interest. In general, the results showed that the pharmacists had low knowledge and practice toward diabetes management. The primary obstacle was lack of training. Hence, they rarely provided pharmaceutical care services, especially in co-morbid disease management which are the main cause of morbidity and mortality. Therefore, training of the healthcare professionals and updating clinical practice protocols with pharmaceutical care services can decrease the progression of any disease.

It is not surprising that the healthcare demands by diabetic patients are high and the pharmacists who did not involve in the disease management will result in poor disease control (Leal et al., 2004; Struijs et al., 2006). It was reported that the short course of pharmaceutical care program on diabetes among community pharmacies in Turkey improved overall glycemic control and blood pressure (Turnacilar et al., 2009).

It must be noted that not only the health status of diabetic patients can be improved by pharmaceutical care practice but also the healthcare expenditure can be reduced (Borges et al., 2011). Another study showed that patients-oriented practice enhances compliance with treatment, decreasing the drug therapy related problem, hence, improving glycemic control (Borges et al., 2010). Moreover, physician-pharmacist collaborative diabetes care was effectively improving glycemic control (Irons et al., 2002). This supports the findings of the present study that the respondents with high diabetic knowledge belief in collaboration between the doctor and the pharmacist. Moreover, other study showed homebased educational program for diabetic patients provided by the pharmacists significantly increase disease-related knowledge and medication adherence (Chow et al., 2016).

On the other hand, the study in Arabic diabetic patients (United Arab Emirate) showed that the nurses or physicians were more effective sources of education for diabetic patients than the pharmacists or dietitians (Abdullah et al., 2001). Other report from Yemen showed that physicians knowledge were higher than pharmacists in diet and insulin dosing, while nurses knowledge were higher than physicians and pharmacists in diabetic foot care (Babelgaith, 2013). These conclusions support the present study findings were the registered and unregistered Iraqi pharmacists had low knowledge toward diabetes. The culture view in Iraq regarding pharmacists role is dispensing only. Moreover, the previous report showed that pharmacists professional performance were under-appreciated by the Iraqi society as a low percent of them showed that the knowledge of the pharmacist will lead them to choose a particular community pharmacy (Ibrahim et al., 2013).

The study results were consistent with the previous report regarding low knowledge and practice toward DM (Shrestha et al., 2015; Erku et al., 2017). In the present study, gender had no effect on DKT score which is consistent with the other study (Odili and Oparah, 2013). It was found that knowledge or clinical skills were the most commonly reported barrier for providing pharmaceutical care practice to diabetic patients in Ethiopia which is similar to the present study (Erku et al., 2017). However, other study in Qatar showed average knowledge and positive attitude toward diabetes while the main obstacles were lack of time, shortage of personnel, and lack of private counseling area (El Hajj et al., 2017).
According to the results, the different educational program must be implemented for Iraqi pharmacists. The pharmacists with good knowledge and positive practice must be encouraged to continue their good practice by offering various motivations like incentives. While the pharmacists with good knowledge and negative practice should be targeted with behavioral changing programs and coping strategies to overcome any obstacles. Moreover, pharmacists with low knowledge and practice should be the main group for intervention to enhance their knowledge and practice. It was reported that 7 hours of continuing education (CE) can increase the DKT scores and the attitude in Taiwanese pharmacists (Chen et al., 2004). Moreover, patient perceptions and necessities must be evaluated by the pharmacists to address the patient needs (Pinto et al., 2006).

Therefore, the CE program is warranted for Iraqi pharmacists. Moreover, a new policy must be implemented to regulate and enhance the role of pharmacists in Iraq. Additionally, offering a new education curriculum or program (like Pharm D. program) in pharmacy schools will increase the role of pharmacists and enhance their knowledge toward disease management. Furthermore, the CE program must be intensively focused on the disease and its proper management.

A cross-sectional study cannot be generalized. The tools used in this study were self-reported, hence, under- or over-reporting variables were possible. However, this study provides valuable information regarding diabetic knowledge and practice among Iraqi pharmacists. This is the first study that showed the urgent needs for effective CE program or changing the study curriculum in Iraqi pharmacy schools to improve chronic illness management.

\section{CONCLUSION}

The present study showed low diabetic knowledge and practice among pharmacists in Iraq. Educational programs are an urgent need to enhance the role and future vision of Iraqi community pharmacists. As well as, a proper guideline covering diabetes care according to the population needs must be issued and implemented in the community pharmacies.

\section{CONFLICTS OF INTERESTS}

The author has none to declare.

\section{FUNDING}

The author has none to declare.

\section{REFERENCES}

Abdulameer SA. Knowledge and pharmaceutical care practice regarding inhaled therapy among registered and unregistered pharmacists: an urgent need for a patient-oriented health care educational program in Iraq. Int J Chron Obstruct Pulmon Dis, 2018; 13:879-88.

Abdullah L, Margolis S, Townsend T. Primary health care patients' knowledge about diabetes in the United Arab Emirates. East Mediterr Health J, 2001; 7:662-70.

American Diabetes Association. Standards of medical care in diabetes-2014. Diabetes Care, 2014; 37:S14-80.

Babelgaith SD. Assessment of the knowledge and practice of health care professionals towards diabetes care in Mukalla, Yemen. IJPTP, $2013 ; 4: 826-31$.

Bisheya AF, El-Mijbri SA, Beshyah SA, Sherif IH. Community pharmacists' knowledge, attitudes and practices in diabetes care in tripoli, Libya. Ibnosina J Med Biomed Sci, 2011; 3:89-95. 
Blenkinsopp A, Hassey A. Effectiveness and acceptability of community pharmacy-based interventions in type 2 diabetes: a critical review of intervention design, pharmacist and patient perspectives. Int $\mathrm{J}$ Pharm Pract, 2005; 13:231-40.

Borges APDS, Guidoni CM, Freitas OD, Pereira LRL. Economic evaluation of outpatients with type 2 diabetes mellitus assisted by a pharmaceutical care service. Arq Bras Endocrinol Metabol, 2011; 55:686-91.

Borges APDS, Guidoni CM, Ferreira LD, Freitas OD, Pereira LRL. The Pharmaceutical care of patients with type 2 diabetes mellitus. Pharm World Sci, 2010; 32:730-6.

Brennan TA, Dollear TJ, Hu M, Matlin OS, Shrank WH, Choudhry NK, Grambley W. An integrated pharmacy-based program improved medication prescription and adherence rates in diabetes patients. Health Aff (Millwood), 2012; 31:120-9.

Chen H-Y, Lee T-Y, Huang W-T, Chang C-J, Chen C-M. The short-term impact of a continuing education program on pharmacists' knowledge and attitudes toward diabetes. Am J Pharm Educ, 2004; 68:121.

Chow EP, Hassali MA, Saleem F, Aljadhey H. Effects of pharmacist-led patient education on diabetes-related knowledge and medication adherence: a home-based study. Health Educ J, 2016; 75:421-33. York, NY, 1977.

Cochran WG. Sampling techniques. John Wiley \& Sons, New

El Hajj MS, Abu Yousef SE, Basri MA. Diabetes care in Qatar: a survey of pharmacists' activities, attitudes and knowledge. Int J Clin Pharm, 2018; 40:84-93.

Erku DA, Belachew SA, Mekuria AB, Haile KT, Melaku B, Tegegn HG, Ayele AA. The role of community pharmacists in patient counseling and health education: a survey of their knowledge and level of involvement in relation to type 2 diabetes mellitus. Integr Pharm Res Pract, 2017; 6:137-43.

Guariguata L, Whiting D, Hambleton I, Beagley J, Linnenkamp U, Shaw J. Global estimates of diabetes prevalence for 2013 and projections for 2035. Diabetes Res Clin Pract, 2014; 103:137-49.

Hermansen-Kobulnicky CJ, Worley MM. Exploring the patient perspective regarding community pharmacists' educational roles in diabetes medication and blood glucose management. Int J Pharm Pract, 2008; 16:81-90.

Ibrahim IR, Al Tukmagi HF, Wayyes A. Attitudes of Iraqi society towards the role of community pharmacists. Inov Pharm, 2013; 4:1-10.

International Diabetes Federation. The IDF Middle East and North Africa (MENA) Region. 2017. Available via https://www.idf.org/ournetwork/regions-members/middle-east-and-north-africa/members/36-iraq. html (Accessed 20 December 2017).

Irons BK, Lenz RJ, Anderson SL, Wharton BL, Habeger B, Anderson HG. A retrospective cohort analysis of the clinical effectiveness of a physician-pharmacist collaborative dsrug therapy management diabetes clinic. Pharmacotherapy, 2002; 22:1294-300.

Karter AJ, Parker MM, Duru OK, Schillinger D, Adler NE, Moffet HH, Adams AS, Chan J, Herman WH, Schmittdiel JA. Impact of a pharmacy benefit change on new use of mail order pharmacy among diabetes patients: the Diabetes Study of Northern California (DISTANCE). Health Serv Res, 2015; 50:537-59.

Kraemer DF, Kradjan WA, Bianco TM, Low JA. A randomized study to assess the impact of pharmacist counseling of employer-based health plan beneficiaries with diabetes: the EMPOWER study. J Pharm Pract, 2012; 25:169-79.
Leal S, Glover JJ, Herrier RN, Felix A. Improving quality of care in diabetes through a comprehensive pharmacist-based disease management program. Diabetes Care, 2004; 27:2983-4.

Mansour AA, Al-Maliky AA, Kasem B, Jabar A, Mosbeh KA. Prevalence of diagnosed and undiagnosed diabetes mellitus in adults aged 19 years and older in Basrah, Iraq. Diabetes Metab Syndr Obes, 2014; 7:139-44.

Odili V, Oparah A. Immediate impact of a diabetes mellitus education programme on the knowledge of pharmacists. West Afr J Pharm, $2013 ; 24: 58-63$.

Perez A, Doloresco F, Hoffman JM, Meek PD, Touchette DR, Vermeulen LC, Schumock GT. Economic evaluations of clinical pharmacy services: 2001-2005. Pharmacotherapy, 2009; 29:128.

Pinto SL, Lively BT, Siganga W, Holiday-Goodman M, Kamm G. Using the Health Belief Model to test factors affecting patient retention in diabetes-related pharmaceutical care services. Res Social Adm Pharm, $2006 ; 2: 38-58$.

Shareef J, Nandakumar U, Bhat M. A study on assessment of adverse drug reactions in patients with Tuberculosis in a tertiary care teaching hospital. J Appl Pharm Sci, 2018; 8:99-104.

Shatnawi A, Latif DA. A qualitative assessment of West Virginia pharmacist activities and attitude in diabetes management. J Eval Clin Pract, 2016; 23:586-92.

Shrestha M, Maharjan R, Prajapati A, Ghimire S, Shrestha N, Banstola A. Assessment of knowledge and practice of community pharmacy personnel on diabetes mellitus management in Kathmandu district: a cross sectional descriptive study. J Diabetes Metab Disord, 2015; 14:71.

Simpson SH, Haggarty S, Johnson JA, Schindel TJ, Tsuyuki RT, Lewanczuk R. Survey of pharmacist activities and attitudes in diabetes management. Can Pharm J (Ott), 2009; 142:128-34.

Smith M. Pharmacists' role in improving diabetes medication management. J Diabetes Sci Technol, 2009; 3:175-9.

Struijs JN, Baan CA, Schellevis FG, Westert GP, Van Den Bos GA. Comorbidity in patients with diabetes mellitus: impact on medical health care utilization. BMC Health Serv Res, 2006; 6:84.

Touchette DR, Doloresco F, Suda KJ, Perez A, Turner S, Jalundhwala Y, Tangonan MC, Hoffman JM. Economic evaluations of clinical pharmacy services: 2006-2010. Pharmacotherapy, 2014; 34:771-93.

Turnacilar M, Sancar M, Apikoglu-Rabus S, Hursitoglu M, Izzettin FV. Improvement of diabetes indices of care by a short pharmaceutical care program. Pharm World Sci, 2009; 31:689-95.

Wertz D, Hou L, Devries A, Dupclay Jr L, Mcgowan F, Malinowski B, Cziraky M. Clinical and economic outcomes of the Cincinnati Pharmacy Coaching Program for diabetes and hypertension. Manag Care, 2012; 21:44-54.

How to cite this article:

Abdulameer SA. A cross-sectional pilot study to investigate diabetic knowledge and pharmaceutical care practice among registered and unregistered pharmacists in Iraq. J App Pharm Sci, 2018; 8(10): 113-121. 